\title{
Biochemical and phenotypic profiling of Bacillus clausii: a potent commercial probiotic
}

\author{
Mothukuru Sandhya Rani ${ }^{1}$, Inamul Hasan Madar ${ }^{2,3}$, Hussain Al Ssadh ${ }^{4}$, Gideon Ikechukwu Ogu ${ }^{5}$ and Iftikhar Aslam Tayubi ${ }^{*}$ \\ ${ }^{1}$ Department of Applied Microbiology, Sri Padmavathi Mahila Visvavidyalayam, Chittoor (Dist), Tirupathi, Andhra Pradesh-517502, India. \\ ${ }^{2}$ Department of Biotechnology \& Genetic Engineering, Bharathidasan University, Tiruchirappalli, 620024, Tamil Nadu, India. \\ ${ }^{3}$ Department of Biomedical Science and Environmental Biology, KMU-Kaohsiung Medical University, Taiwan. \\ ${ }^{4}$ School of Biological sciences, University of Essex, Colchester, CO43SQ, United Kingdom. \\ ${ }^{5}$ Department of Biological Sciences, Novena University, Ogume, Delta State, Nigeria. \\ ${ }^{6}$ Faculty of Computing and Information Technology, King Abdul-Aziz University, Rabigh-21911, Saudi Arabia.
}

\begin{tabular}{|c|c|}
\hline ARTICLE INFO & ABSTRACT \\
\hline $\begin{array}{l}\text { Key words: } \\
\text { Probiotics, Bacillus clausii, } \\
\text { phenotypic, antibiotic } \\
\text { susceptibility, sequence } \\
\text { alignment, phylogenetic tree, } \\
\text { and population genetics }\end{array}$ & $\begin{array}{l}\text { The popularity of the probiotics in India has expanded exponentially as they facilitate the host animals in improving the } \\
\text { intestinal imbalance of microbial flora. They can be administered as pellets, capsules, paste, powder, curd, granules and } \\
\text { also in form of suspensions. In some countries probiotics are also taken as prophylactic agents. Bacillus clausii spore } \\
\text { suspension is a probiotic of choice in the treatment of diarrhoea and prevention of antibiotic associated diarrhoea. The } \\
\text { spores have catapulted themselves as the prescription choice for the treatment of diarrhoea in India. In the present study, } \\
\text { three commercially available Bacillus clausii spore suspensions were collected for the phenotypic characterization and } \\
\text { biochemical analysis. The optimal viability assay conditions and the antibiotic susceptibility assay profiles are } \\
\text { determined. The optimization of the key parameters is also presented. Sequence alignment was performed to check the } \\
\text { evolutionary relationship of Bacillus clausii with organisms of different taxa. Statistical study was performed by using } \\
\text { BEAST and a tree was constructed. }\end{array}$ \\
\hline
\end{tabular}

\section{INTRODUCTION}

The Roman historians recommended the administration of formulated milk products for treating gastroenteritis in 76 B.C [1]. Oral bacteria therapy is generally marketed by using Bacillus species because of their ability to treat or prevent various gastrointestinal disorders. Probiotics are being developed commercially as novel foods or dietary supplements for human use and they are used in animal feeds for the prevention of gastrointestinal infections [2]. The market demand indicates that it is economically viable product [3]. In human gastrointestinal environment, Bacillus spores survive and can undergo germination and multiplication as vegetative forms [4]. It has been shown that spore mixture of $\mathrm{B}$. clausii comprising of four strains (O/C, SIN, N/R and T) are resistant to wide range of antibiotics and are marketed as OTC medicinal supplement [5].

\section{*Corresponding Author}

Dr. Iftikhar Aslam Tayubi, Faculty of Computing and Information Technology, King Abdul-Aziz University, Rabigh-21911, Saudi Arabia. E-mail: eislam@kau.edu.sa
Spores are heat stable, capable of surviving the low $\mathrm{pH}$ and products made from them can be stored at room temperature without any deleterious effect on viability $[6,7]$. The phenotypic characterization of microbial strains acclimated as probiotics thus far represents the alone identification approach, although this alignment consistently leaves uncertainties and adversity of interpretation. Moreover, a number of papers have stated inaccuracies in phenotype based speciation of microbial strains [8]. BLAST is a quick sequence comparison tool that uses an investigative approach to construct alignments by enhancing a measure of local similarity. Since BLAST compares protein and nucleotide sequences considerably more rapidly than dynamic programming methods such as Smith-Waterman and Needleman-Wunsch, it is extensively used for database searches [9].

BEAST is a quick, adaptable software architecture for Bayesian analysis of molecular sequences related by an evolutionary tree. A huge number of popular stochastic models of sequence evolution are given and tree-based models appropriate for both within- and between-species sequence data are executed [10]. In the present study, Bacillus clausii probiotic products were examined based upon the quality tests by microbial limit identification, biochemical analysis, phenotypic characterization and optimization of the key parameters for temperature, $\mathrm{pH}$ and alkaline tolerance. The quantity tests and different viable counts were also carried out. 
Local sequence alignment of the Tetracycline resistance protein for Bacillus clausii was done and analysed. Population genetics analysis has been done and a phylogenetic tree has been constructed.

\section{MATERIALS AND METHODS}

\section{Sample collection}

Bacillus clausii spore suspension commercial samples have been collected from India and are named as: Sample1, Sample2 and Sample3. These strains acquired based upon their resistance to different antibiotic resistance markers: O/C (aggressive to Chloramphenicol), SIN (aggressive to Neomycin and Streptomycin), N/R (aggressive to Novobiocin) and Rifampicin and T (aggressive to Tetracycline).

\section{Culture conditions:}

The strains were maintained on LB agar plates at $35^{\circ} \mathrm{C}$. For biochemical studies, bacteria were inoculated with LB supplemented and growth performance was studied by using $250 \mathrm{ml}$ flasks containing $100 \mathrm{ml} \mathrm{LB}$ broth at $\mathrm{pH}$ 8.0. The broth cultures were incubated at $35^{\circ} \mathrm{C}$ for 48 hours in an orbital shaker at $250 \mathrm{rpm}$. Optical density was observed at $600 \mathrm{~nm}$. Culture medium containing cells were collected at stationary growth phase after $24 \mathrm{hr}$ for further study. The experiment was performed in duplicates for each Bacillus clausii strain.

\section{Screening of the antibiotic resistance strains:}

The collected samples were analysed for microbial enumeration test by using XLDA (Xylose Lysine Deoxycholate Agar), MSA (Mannitol Salt Agar), Mc Agar (Mcconkey agar), CET (Cetrimide agar) SCDA (SoyabeanCaesin Digest Agar) and SDA (SabourdDextose Agar). Fivefold dilution of samples were performed and $0.5 \mathrm{ml}$ of the sample was taken into media plates (Trytone $10.0 \mathrm{~g}$, Yeast Extract 5.0g, $\mathrm{NaCl} 5.0 \mathrm{~g}, \mathrm{DD} \mathrm{H} 2 \mathrm{O} 1.0 \mathrm{~L}$ ) containing $50 \mu \mathrm{g} / \mathrm{mL}$

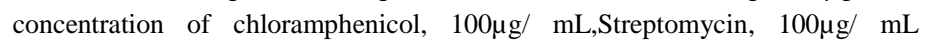
Tetracycline and $100 \mu \mathrm{g} / \mathrm{mL}$ rifampin.

The number of colonies were identified by using plate count method the initial number of viable organisms in the sample was calculated from the number of colonies formed multiplied by the dilution factor [11, 12]. Broth dilution technique was used for antibiotic resistance assay as the technique is relatively simple for manual testing of small numbers of cultures [13]. Phenotypic observations for the strain were studied according to Berry's manual of system bacteriology. Single colony isolates were stored in a glycerol stock solution at $80^{\circ} \mathrm{C}$ for further study.

\section{Antibiotic susceptibility assays:}

Minimum inhibitory concentration (MIC) for selected antibiotics was identified by using disc diffusion method with $30 \mu \mathrm{g} / \mathrm{mL}, 50 \mu \mathrm{g} / \mathrm{mL}$ and $100 \mu \mathrm{g} / \mathrm{mL}$ concentration of Rifampicin, Chloramphenicol, Tetracycline and Streptomycin antibiotics individually for all the strains with both positive and negative controls.

\section{Optimization parameters:}

Optimization key parameters are temperature and $\mathrm{pH}$ were studied. The effect of temperature was studied from $35^{\circ} \mathrm{C}$ to $75^{\circ} \mathrm{C}$ and the effect of $\mathrm{pH}$ was studied from $\mathrm{pH} 5$ - 11. Temperature is a critical parameter that has to be controlled and varied from organism to organism for maximum cell growth.

\section{Alkaline tolerance study:}

Tolerance for alkalinity for Bacillus clausii were studied by using $2-10 \%$ $\mathrm{NaCl}$ by culturing the bacterial cell cultures on $\mathrm{LB}$ agar buffered at $\mathrm{pH}$ 8.0. The cultures were then incubated at $35^{\circ} \mathrm{C}$ for $24 \mathrm{hr}$ at $120 \mathrm{RPM}$.

\section{Effect of Temperature for activation of spores:}

The transition of every stage from spore to vegetative cell activation, germination and outgrowth has a characteristic response to the temperature. Optimal activation temperatures are generally considerably higher than the optima for germination and outgrowth [14]. The effect of the temperature on spores for the activation stage was studied by giving heat shock treatment to the spores from $35^{\circ} \mathrm{C}$ to $75^{\circ} \mathrm{C}$. Sample was collected at 30 and 60 minutes from water bath incubator shaker (Royal scientific). Spotted 100uL of the above prepared dilutions on the agar plates and incubated for $48 \mathrm{hr}$ for viable count.

\section{Local sequence alignment:}

The programme used for sequence alignment BLASTP, the Local search alignment tool for protein sequences often contains high scoring segment pairs between the query sequence and sequences in the database. For query sequence, we used Tetracycline resistance protein of Bacillus clausii having 647 amino acid query length with the non-redundant protein database of NCBI. For amino acid queries, the low complexity regions were selected by the SEG program and the filter was allowed in the search. The algorithm parameters were kept in default settings.

\section{Population Genetics Studies:}

Statistical inferences of the above-mentioned studies were performed by using the Bayesian Evolutionary Analysis Sampling Tree (BEAST). The XML file was generated by the BEAUTi, a graphical user interface. Tree model was selected as a random starting model for ease of interpretation of the results. Default settings were chosen for simplicity to record the sample states that Makarov chain has encountered. Two different file formats .log and. tree was generated for further analysis by the TRACER and FigTree respectively.

\section{RESULTS AND DISCUSSION}

There is a growing surge of interest in the Bacillus clausii spore suspension products. Comprehensive studies of the Bacillus clausii products manufactured in India are virtually non-existent. The present study is the first attempt in this direction. Biochemical analysis and phenotypic characterization was carried out. Spectrophotometric quantification of the sample 0.8 OD was quantified and the samples reach the viable count on the agar plate. Samples were analysed for microbial growth examination. Growth was observed in SCDA and SDA media plates and no growth was observed in XLDA, MSA, CET agar and MCA agar plates. In the following results (Table1) the symbols ' + ' indicates the result was positive and the symbol '- indicates the result was negative. Phenotypical and biochemical examination for Bacillus clausii samples were as follows Table 2. The grampositive, rod-shaped Bacillus clausii showed negative results for the hydrolysis of Tween 20 and Tween 80 . Similar observations were corresponded with results of Nielsen et.al. 1995 [15] for phenotypic and biochemical properties of the strain Bacillus clausii. 
According to well-known spore biology, Bacillus clausii spores shows growth in Positive control shows inhibition zones. No growth was observed in negative the diluted sample containing antibiotic agar plates. Viable spores were observed controls and tolerate acidity up to $10 \%$ were considered critical levels for when the spores were grown in plates supplemented with Tetracycline, tolerance, respectively for probiotics. The sample shows similar results of the Chloramphenicol, Streptomycin, and Rifampicin Table 3. The MIC was Bacillus clausii aqueous suspension with literature where there is similarity in evaluated by Disc diffusion method Table 4 . results between the samples [15].

Table 1. Microbial growth examination in specified media

\begin{tabular}{|c|c|c|c|}
\hline Media & Sample1 & Sample2 & Sample3 \\
\hline XLDA & - & - & - \\
\hline MSA & - & - & - \\
\hline MCA & - & - & - \\
\hline CET & - & + & + \\
\hline SCDA & + & + & + \\
\hline SDA & + & + & + \\
\hline
\end{tabular}

Table 2. Phenotypic and Biochemical characteristics of B. clausii

\begin{tabular}{|c|c|}
\hline Characteristics & Observations \\
\hline Colony Shape & Circular \\
\hline Colony Size & $0.8-1.0 \mathrm{~mm}$ \\
\hline Form & Circular \\
\hline Elevation & Slightly raised low convex \\
\hline Colony margin & Filamentous \\
\hline Surface & Shiny smooth \\
\hline Color & Creamy white \\
\hline Gram's stain & + \\
\hline Cell shape & Rod shape \\
\hline Endospores & + \\
\hline Motility & + \\
\hline Caesin hydrolysis & + \\
\hline Starch hydrolysis & + \\
\hline Gelatin hydrolysis & + \\
\hline Tween hydrolysis 20 & - \\
\hline Tween hydrolysis 80 & - \\
\hline Oxidase test & + \\
\hline Catalase test & + \\
\hline
\end{tabular}

Table 3. Viability count in media plates

\begin{tabular}{|c|c|c|c|}
\hline Colonies Observed $\left(10^{-6}\right)$ & Sample1 & Sample2 & Sample3 \\
\hline Tetracycline & 37 & 35 & 33 \\
\hline Chloramphenicol & 36 & 28 & 28 \\
\hline Rimfampin & 37 & 37 & 32 \\
\hline Streptomycin & 32 & 35 & \\
\hline
\end{tabular}


Table 4. Minimum Inhibitory diameter

\begin{tabular}{|c|c|c|c|}
\hline $\begin{array}{l}\text { Minimum Inhibitory } \\
\text { Concentration (mm) }\end{array}$ & Sample1 & Sample2 & Sample3 \\
\hline Tetracycline $(30 \mu \mathrm{g} / \mathrm{ml})$ & $10 \pm 1$ & $11 \pm 0.8$ & $11 \pm 0.5$ \\
\hline Tetracycline $(50 \mu \mathrm{g} / \mathrm{ml})$ & $18 \pm 0.5$ & $15 \pm 1$ & $16 \pm 1$ \\
\hline Tetracycline $(100 \mu \mathrm{g} / \mathrm{ml})$ & $25 \pm 1$ & $23 \pm 0.8$ & $24 \pm 0.5$ \\
\hline Chloramphenicol $(30 \mu \mathrm{g} / \mathrm{ml})$ & $16 \pm 0.5$ & 13 & $15 \pm 0.5$ \\
\hline Chloramphenicol $(50 \mu \mathrm{g} / \mathrm{ml})$ & $18 \pm 0.5$ & $18 \pm 1$ & $18 \pm 0.5$ \\
\hline Chloramphenicol $(100 \mu \mathrm{g} / \mathrm{ml})$ & $19 \pm 0.5$ & $19 \pm 0.5$ & $19 \pm 0.5$ \\
\hline $\operatorname{Rimfampin}(30 \mu \mathrm{g} / \mathrm{ml})$ & $7 \pm 0.8$ & $7 \pm 0.5$ & $7 \pm 0.8$ \\
\hline Rimfampin $(50 \mu \mathrm{g} / \mathrm{ml})$ & $12 \pm 0.8$ & $12 \pm 0.5$ & $12 \pm 0.5$ \\
\hline Rimfampin $(100 \mu \mathrm{g} / \mathrm{ml})$ & $17 \pm 0.8$ & 14 & $14 \pm 0.5$ \\
\hline Streptomycin $(30 \mu \mathrm{g} / \mathrm{ml})$ & $18 \pm 0.5$ & $17 \pm 0.8$ & $17 \pm 0.6$ \\
\hline Streptomycin $(50 \mu \mathrm{g} / \mathrm{ml})$ & $20 \pm 0.5$ & $19 \pm 1$ & $19 \pm 0.8$ \\
\hline Streptomycin $(100 \mu \mathrm{g} / \mathrm{ml})$ & $22 \pm 0.5$ & $22 \pm 1$ & $23 \pm 0.5$ \\
\hline
\end{tabular}

Table 5. NaCl tolerance Test for B. Clausii Spores

\begin{tabular}{|c|c|}
\hline NaCl Concentration & Observation \\
\hline $2 \% \mathrm{NaCl}$ & + \\
\hline $4 \% \mathrm{NaCl}$ & + \\
\hline $6 \% \mathrm{NaCl}$ & + \\
\hline $8 \% \mathrm{NaCl}$ & + \\
\hline $10 \% \mathrm{NaCl}$ & + \\
\hline
\end{tabular}

Table 6. Effect of temperature

\begin{tabular}{|c|c|}
\hline Temperature & Observation \\
\hline $35^{\circ} \mathrm{C}$ & + \\
\hline $40^{\circ} \mathrm{C}$ & + \\
\hline $45^{\circ} \mathrm{C}$ & + \\
\hline $50^{\circ} \mathrm{C}$ & + \\
\hline $55^{\circ} \mathrm{C}$ & + \\
\hline $60^{\circ} \mathrm{C}$ & + \\
\hline $65^{\circ} \mathrm{C}$ & + \\
\hline
\end{tabular}

All strains have shown growth at $8 \% \mathrm{NaCl}$ and strains grew well in $2 \%-10 \%$ A range of environmental factors are crucial in heat activation and it must be $\mathrm{NaCl}$ after which the cell count was decrease drastically. The effect of carried out in the presence of water. Bacillus subtilis spore's maximum temperature on Maximum Cell Growth was studied and the optimum growth was germination rate requires $75^{\circ} \mathrm{C}$ heat activation time of 15 min [17]. Bacillus observed at $35^{\circ} \mathrm{C}$. The temperature required for spore activation reveals that cereus maximal temperatures are above $59^{\circ} \mathrm{C}$ and $80^{\circ} \mathrm{C}$ was found to be the there may be an increase in spore germination with an increase in temperature. highest temperature. Floating of a microbial culture for 30 min on distilled water Maximum spore germination was observed to be at $65^{\circ} \mathrm{C}$ for 30 minutes and 60 at $60^{\circ} \mathrm{C}$ had no effect on the spore or on its germination [18]. minutes of heat treatment.

The strain had similar spore germination profiles with germination taking place between $30-60$ minutes underlying the fact that they share common mechanism for activation. An apparent access in the sporulation ability was observed when temperature of incubation was shifted from $80^{\circ} \mathrm{C}\left(38 \%\right.$ efficiency) to $65^{\circ} \mathrm{C}(100$ $\%$ efficiency) in case of $\mathrm{B}$. aerius, advertence that the spores of B. aerius, are able to sustain a Temperature of $80^{\circ} \mathrm{C}, \mathrm{B}$. cereus, failed to show any sporulation at $80^{\circ} \mathrm{C}$ but could speculated efficiency at $65^{\circ} \mathrm{C}(100 \%)$ [16].
Increasing the temperature of heat activation (aqueous suspension, $5 \mathrm{ml}$ ) increases the germination ability of the spores. Activation as measured by way of extent germination, changed into most effective after heating at $45^{\circ} \mathrm{C}$ to $75^{\circ} \mathrm{C}$ and the rate of the spore activation was maximal afterheat activation at $45^{\circ} \mathrm{C}-75^{\circ} \mathrm{C}$ (Figure1, Figure2 and Figure3). Increasing the temperature of activation above $45^{\circ} \mathrm{C}$ for one hour decreased the germination rate. Germination was passed off over an extensive range of temperatures, but turned into most suitable for aqueous suspension of the sample $35^{\circ} \mathrm{C}$ (figure 1). 


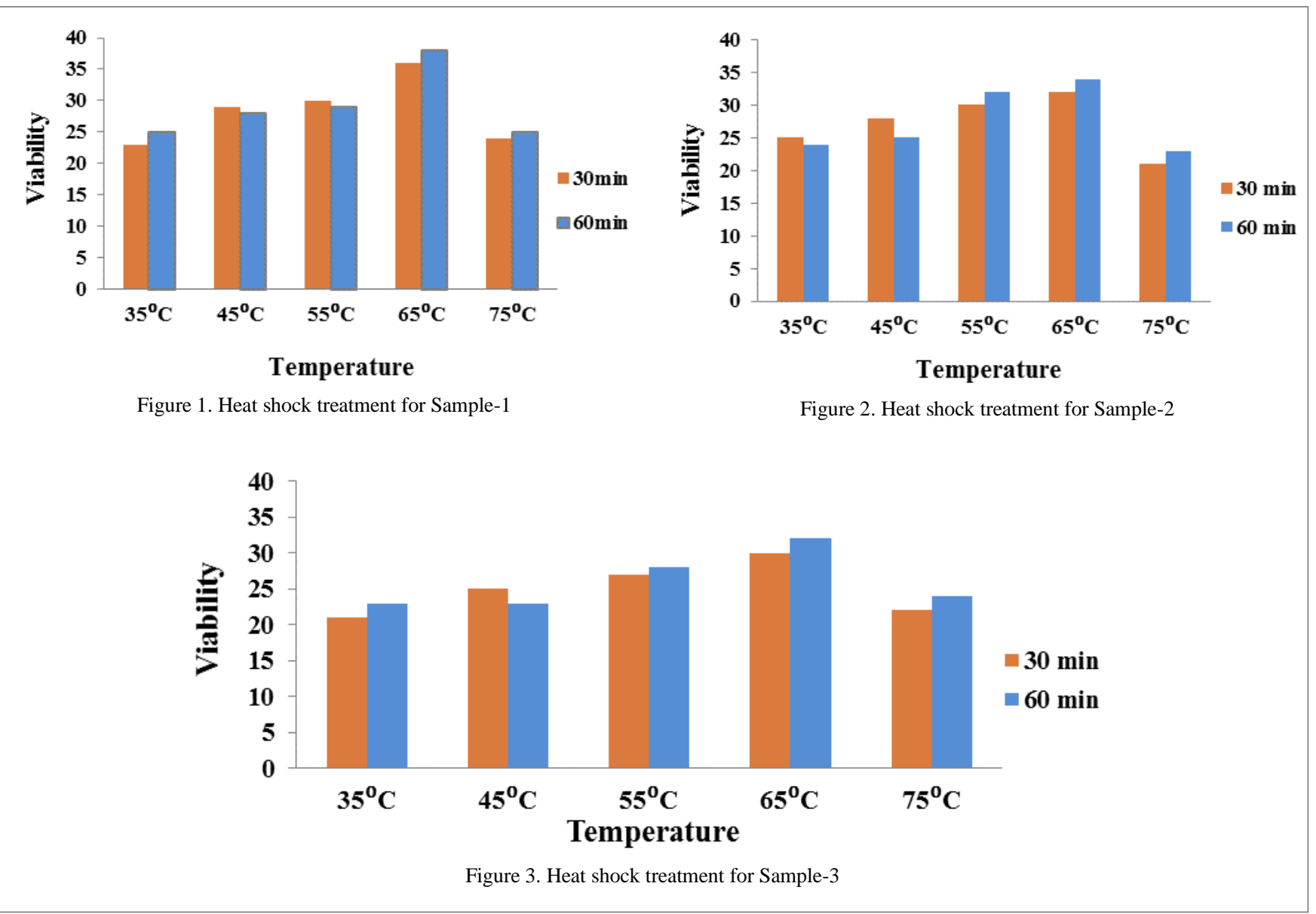

For assessment of the maximum cell increase, the cells were subjected to different ph. conditions which ranged from $\mathrm{pH} 5$ - 11. Bacillus clausii suggests lush growth at $\mathrm{pH} 6,7,8,9$ and 10 suggests comparable growth. There was no increase in growth at $\mathrm{pH} 5$ and $\mathrm{pH} 11$. The unique species of spores seem to show off one of the kind levels of resistance to acid environment and thus entail individual characterization of each species. Bacillus clausii spores can survive the gastric $\mathrm{pH}$, activate and reach the intestinal tract where they germinate to vegetative form $[19,20]$. The $\mathrm{pH}$ of Bacillus clausii was sensitive to extreme acidic and basic environments. These observations can comply the Bacillus clausii products where in the presence of acidic or fundamental recipients can have an effect on the $\mathrm{pH}$ of the microenvironment. Cenci et.al. (2006) [21].

Table 7. Growth Observations on different $\mathrm{pH}$

\begin{tabular}{|c|c|}
\hline $\mathrm{pH}$ & Observation \\
\hline $\mathrm{pH} 5$ & - \\
\hline $\mathrm{pH} \mathrm{6}$ & + \\
\hline $\mathrm{pH} \mathrm{7}$ & + \\
\hline $\mathrm{pH} 8$ & + \\
\hline $\mathrm{pH} 9$ & + \\
\hline $\mathrm{pH} \mathrm{10}$ & + \\
\hline $\mathrm{pH} \mathrm{11}$ & - \\
\hline
\end{tabular}

Suggested that no relevant diff-erences were found studying the growth at $\mathrm{pH} 8$ and 10, whereas at $\mathrm{pH} 7$ the yields obtained for $\mathrm{O} / \mathrm{C}$ and $\mathrm{SIN}$ were higher than those obtained for N/R and $\mathrm{T}$ strains. Some of the suggested defensive strategies to deal with the $\mathrm{pH}$ instability are microencapsulation by enteric polymers like cellulose phthalate [22]. Coating of probiotics with lipidic excipients like waxes [23]. Mixing with resistant starch [24] and symbiotic microencapsulation by emulsion spray drying technique [25].

\section{Local Sequence alignment}

BLAST is a sequence alignment tool which optimizes a measure of the local similarity, the maximal segment pair for a given set of sequences. Similarity among the sequences was observed for the tetracycline resistance protein of Bacillus clausii (PAF09740.1). Ten sequences were selected based on the expected value (E-Value), the maximal score and the identity value. The lesser the $\mathrm{E}$ value a search, the more significant it is showing there was less background noise in each hit. Low complexity regions showed conserved domains responsible for the function of the protein in the study Bacillus clausii (PAF09740.1).

Ten sequences were selected based on the expected value (E-Value), the maximal score and the identity value. The lesser the $\mathrm{E}$ value a search, the more significant it is showing there was less background noise in each hit. Low complexity regions showed conserved domains responsible for the function of the protein in the study. By applying the filter in the BLASTP search one can expect to find out the domains which are similar to other species. 


\section{Color Key for alignment scores}

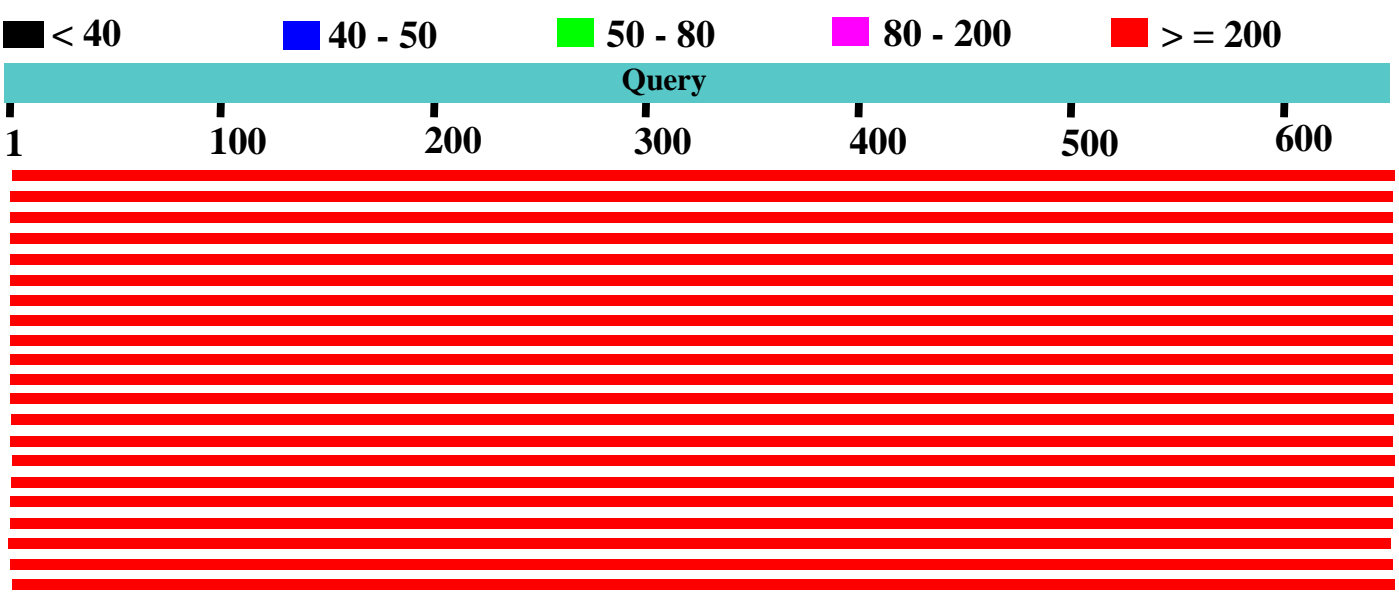

Figure 5. Low Complexity regions filters depict the low conserved domains

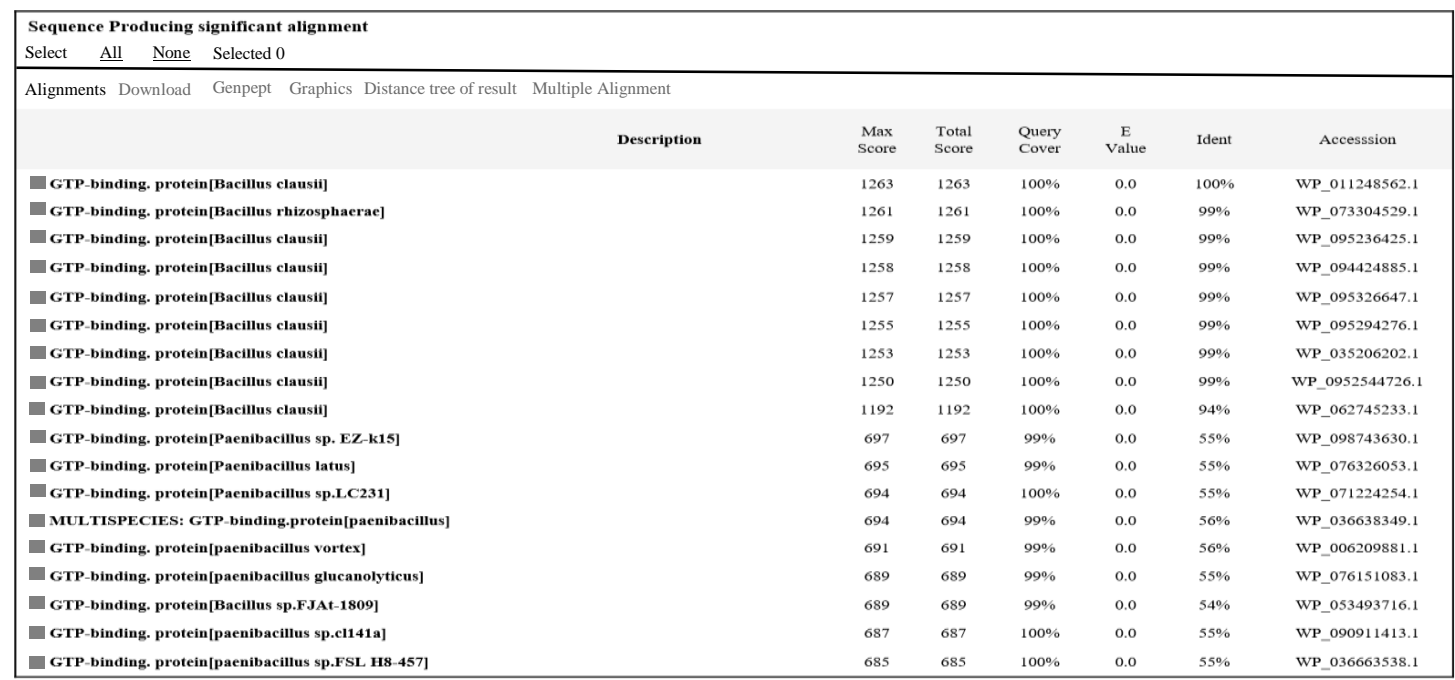

Figure 6. Putative hits in BLASTP having sequences with significant alignments with scores and accession number

This helps us in telling the protein of the interest is a homologous protein and its Differential homology was observed with different species in the rooted tree gene expression is evolutionary conserved. The results given by the BLASTP are constructed with Bacillus rizosphareae being the closest neighbor in speciation distributions of the blast hits on the query sequence are shown in the following with branch 0.8333 . For validating a tree, a bootstrap method is used which tells figure, the alignments are color coded ranging from black to red as indicated in us that each branch length of a tree should be less than 0.90 value for it to be the color label at the top of figure 5. The hits are colored according to the used in evolutionary studies. The current tree constructed correlates with the obtained aligned scores. Multiple sequence alignment is the skeletal frame for bootstrap values. Different colors indicate the different taxa with the speciation any tree construction software. A consensus sequence can be obtained after event separating the species. The branch length is indicated by the numerical performing the multiple alignments which in turn helps invalidation of the tree. value which is calculated by the NJ method of the tree construction. The tree is The BLASTP finds regions of local and global similarity between protein validated by seeing the branch length as a bootstrap parameter.

sequences. $100 \%$ similarity was observed GTP-binding protein [Bacillus clausii] and very less similarity with WP_073304529.1 accession number in the NCBI database. It is important to search sequence databases to find homologous sequences to reach the better understanding of biological systems at the gene level.

\section{Tree construction}

Species selected from the BLAST were analyzed by the BEAST and tree was constructed by using Figtree.

\section{Statistical Inferences}

Tracer is used to produce estimates of the parameters of interest like evolutionary rates, divergence times, population sizes and tree topologies. Trace selected for the study was treeModel.root because it's provide the statistical data to infer the evolutionary distances between the selected species and gives an insight in the speciation event and lineage distribution. The effective sample size (ESS) was high which indicates the current analysis did yield a sufficient number of independent samples from the posterior distribution for that parameter. 


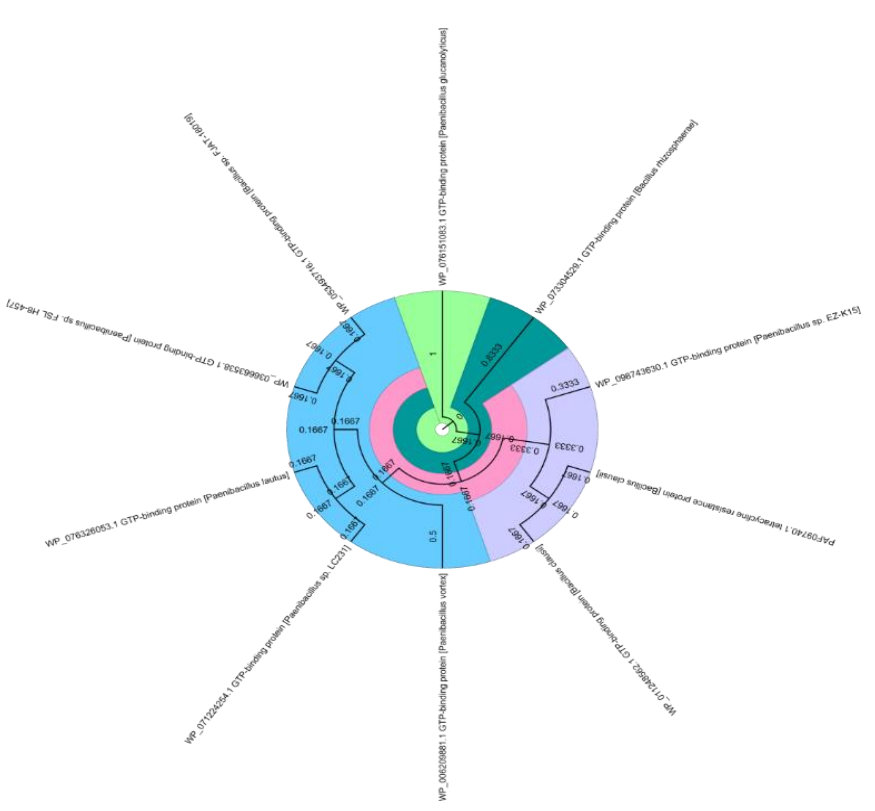

Figure 7. Radial rooted tree constructed by using Figtree

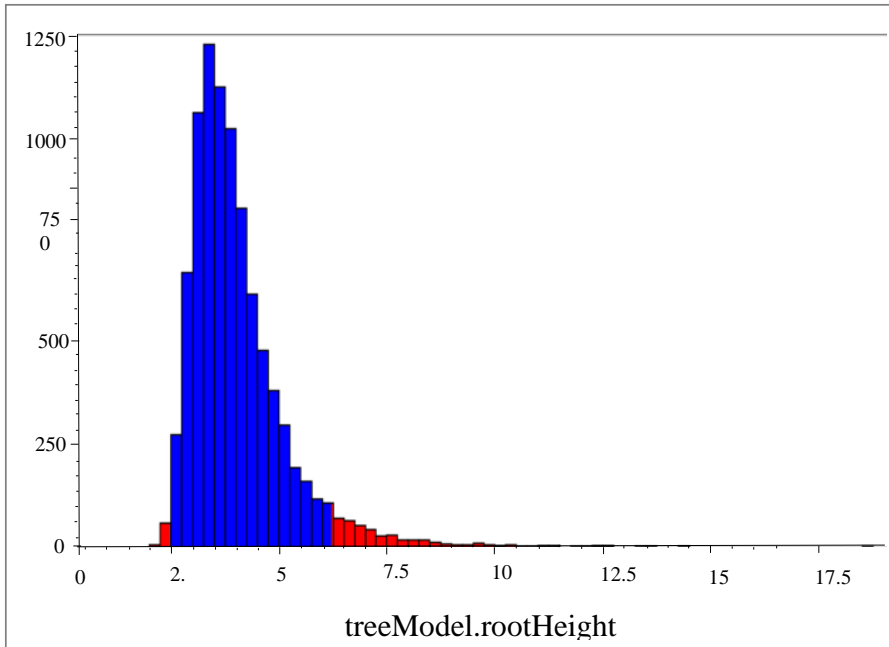

Figure 8. Mean estimates of the tree likelihood from the TRACER

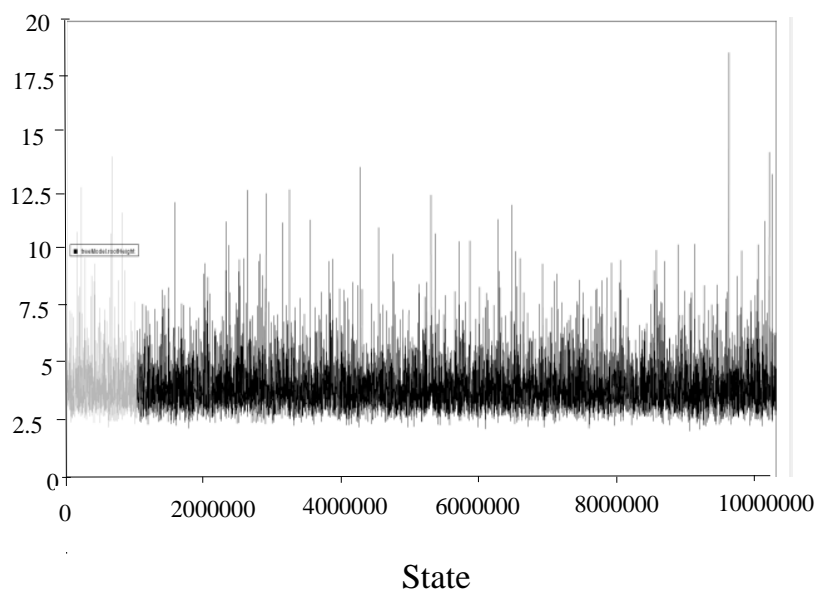

Figure 9. Trace result of all the breakage happened in the BEAST run on the Makarov chain
Autocorrelation time(ACT) indicate the number of states in the MCMC chain that two samples have to be from each other for them to be uncorrelated. Its high value indicates that the samples selected are not biased and selection of the samples is statistically correct. By selecting the trace panel one can view the raw trace, that is, the sampled values against the step in the MCMC chain. Posterior probability is calculated by the Makarov chain estimates using the Bayesian algorithm for the effective sample size. Height ESS value indicates that the species selected under the study are unbiased and the tree generated is validated. When running a BEAST XML file, sometimes breakage happens because of the trace and log parameters 9 being large enough. The likelihood is captured and plotted against the $\log$ of how much tracer has repaired the breakage. This depicts the authenticity of the results.
The current experimentation with insilico evaluation evidenced that the species under study matches with well-marked probiotics. The parameters under consideration were optimized to reach the level of excellence. Hence, the manipulated conditions for probiotics will help in the commercialization of the product to treat intestinal flora imbalance.

\section{Conclusion}

In conclusion Bacillus clausii spore suspension can be used as a source of improving the intenstinal imbalance of microbial floara, it helps in effective treatment of ill-health condtions such as diarrhea and other intestinal malfunctions. There are already few capsulated probiotics in market which is a method of choice of the treatment for the clinicians. 


\section{ACKNOWLEDGMENTS}

Authors acknowledge the support of Department of Applied Microbiology, Sri Padmavathi Mahila Visvavidyalayam, Tirupathi, and Andhra Pradesh, India. Department of Biomedical Science and Environmental Biology, KMU-Kaohsiung Medical University, Taiwan. Department of Biological Sciences, Novena University, Ogume, Delta State, Nigeria. Faculty of Computing and Information Technology, King Abdul-Aziz University, Rabigh, Saudi Arabia and School of Biological sciences, University of Essex, United Kingdom.

\section{CONFLICT OF INTEREST}

The authors declare that there is no conflict of interest.

\section{REFERENCES}

[1] Bottazzi V (1983) Food and feed production with microorganisms. Biotechnology. 5(1): 315-363. (Crossref)

[2] Hong HA, Duc LH, Cutting SM (2005). The use of bacterial spore formers as probiotics. FEMS microbiology reviews. 29(4): 813-835. (Crossref)

[3] Meena GS, Gupta S, Majumdar GC, (2011) Growth characteristics modeling of Bifidobacterium bifidum using RSM and ANN. Brazilian Archives of Biology and Technology. 54(6): 1357-1366. (Crossref)

[4] Ghelardi E, Celandroni F, Salvetti S, Gueye SA, Lupetti A, et al. (2015) Survival and persistence of B acillus clausii in the human gastrointestinal tract following oral administration as spore-based probiotic formulation. Journal of applied microbiology. 119(2): 552-559. (Crossref)

[5] Ciffo F (1984) Determination of the spectrum of antibiotic resistance of the" Bacillus subtilis" strains of Enterogermina. Chemioterapia: international journal of the Mediterranean Society of Chemotherapy. 3(1): 45-52.

[6] Spinosa MR, Braccini T, Ricca E, De Felice M, Morelli L, et al. (2000) on the fate of ingested Bacillus spores. Research in Microbiology. 151(5): 361-8. (Crossref)

[7] Cutting SM (2011) Bacillus probiotics. Food microbiology. 28(2): 214-20. (Crossref)

[8] Donelli G, Vuotto C, Mastromarino P (2013) Phenotyping and genotyping are both essential to identify and classify a probiotic microorganism. Microbial ecology in health and disease. 24(1): 20105. (Crossref)

[9] Tatusova TA, Madden TL (1999) BLAST 2 Sequences, a new tool for comparing protein and nucleotide sequences. FEMS microbiology letters. 174(2): 247-50. (Crossref)

[10] Drummond AJ, Rambaut A (2007) BEAST: Bayesian evolutionary analysis by sampling trees. BMC evolutionary biology. 7(1): 214-227. (Crossref)

[11] Li RC, Lee SW, Lam JS (1996) Novel method for assessing postantibiotic effect by using the Coulter counter. Antimicrobial agents and chemotherapy. 40(7): 1751-1773.
[12] Madigan MT, Martinko JM, Parker J (1997) Brock biology of microorganisms. Upper Saddle River, NJ: Prentice hall.

[13] Evans JB, Harrell LJ (1977) Agar shake tube technique for simultaneous determination of aerobic and anaerobic susceptibility to antibiotics. Antimicrobial agents and chemotherapy. 12(4): 534-546. (Crossref)

[14] Levinson HS, Hyatt MT (1970) Effects of temperature on activation, germination, and outgrowth of Bacillus megaterium spores. Journal of bacteriology. 101(1): 58-64.

[15] Nielsen P, Fritze D, Priest FG (1995) Phenetic diversity of alkaliphilic Bacillus strains: proposal for nine new species. Microbiology. 141(1): 1745-1761. (Crossref)

[16] Barbosa TM, Serra CR, La Ragione RM, Woodward MJ, Henriques AO (2005) Screening for Bacillus isolates in the broiler gastrointestinal tract. Applied and environmental microbiology. 71(2): 968-78. (Crossref)

[17] Luu S, Cruz-Mora J, Setlow B, Feeherry FE, Doona CJ, et al (2015) The effects of heat activation on Bacillus spore germination, with nutrients or under high pressure, with or without various germination proteins. Applied and environmental microbiology. 81(8):2927-38. (Crossref)

[18] Knaysi G (1964) Effect of temperature on the rate of germination in Bacillus cereus. Journal of bacteriology. 87(3): 619-22.

[19] Ciffo F, Dacarro C, Giovanetti M, Mazza PG (1987) Gastric resistance of Bacillus subtilis spores used in oral bacteriotherapy: in vitro studies. Farmaci e terapia. 3(2): 163-9.

[20] Urdaci MC, Bressollier P, Pinchuk I (2004) Bacillus clausii probiotic strains: antimicrobial and immunomodulatory activities. Journal of clinical gastroenterology. 38: S86-90. (

[21] Cenci G, Trotta F, Caldini G. Tolerance to challenges miming gastrointestinal transit by spores and vegetative cells of Bacillus clausii. Journal of applied microbiology. 101(6): 1208-15. (Crossref)

[22] Favaro-Trindade CS, Grosso CR (2002) Microencapsulation of L. acidophilus (La-05) and $\mathrm{B}$. lactis (Bb-12) and evaluation of their survival at the $\mathrm{pH}$ values of the stomach and in bile. Journal of microencapsulation. 19(4):485-94. (ㄷossref)

[23] Durand H, Panes J, inventors; Lallemand SA, assignee (2007) Particles containing coated living micro-organisms, and method for producing same. United States patent US 7,157,258.

[24] Brown IL, McNaught KJ, Ganly RN, Conway PL, Evans AJ, Topping DL, Wang X, inventos; (2000) Commonwealth Scientific, Industrial Research Organization (CSIRO), Goodman Fielder Wattie Australia Ltd, Arnott's Biscuits Ltd, assignee. Probiotic compositions. United States patent US $6,060,050$.

[25] Crittenden R, Weerakkody R, Sanguansri L, Augustin M (2006) Synbiotic microcapsules that enhance microbial viability during nonrefrigerated storage and gastrointestinal transit. Applied and environmental microbiology. 72(3): 2280-2. (Crossref)

How to Cited this article:

Rani MS, Madar IH, Al Ssadh H, Ogu GI and Tayubi IA (2018) Biochemical and phenotypic profiling of Bacillus clausii: a potent commercial probiotic. Int J Sci Innovs. 5 (3): 099-106. 